\title{
Políticas de Estado en el modelo de prensa anglosajón'
}

\author{
Guadalupe Aguado Guadalupe \\ Universidad Carlos III de Madrid \\ maguado@hum.uc3m.es \\ Josep María SANMARTí Roset \\ Universidad Carlos III de Madrid \\ jsanmart@hum.uc3m.es \\ Raúl Magallón Rosa \\ Universidad Carlos III de Madrid \\ raul.magallon@uc3m.es
}

Recibido: 25/02/2011

Aceptado: 6/09/2011

\section{Resumen}

Además de la lengua, los países de cultura anglosajona comparten en gran medida unos orígenes parecidos para sus respectivos sistemas de prensa y un marco democrático y empresarial sin interrupciones señaladas. Pero por otro lado, cada país ha seguido una evolución distinta marcada fundamentalmente por las relaciones entre el Estado y la Prensa. Desde este ángulo EEUU ha sido el país menos intervencionista, seguido por Gran Bretaña. Irlanda y Australia, por el contrario, han aplicado leyes y normas destinadas a combatir aspectos tan distintos como la difamación, la blasfemia, la publicación de secretos oficiales o la concentración de empresas. Sin duda, los nuevos retos planteados por los medios audiovisuales y digitales y la crisis económica mundial están obligando a una revisión de los cuatro modelos nacionales.

Palabras clave: Prensa en Estados Unidos, prensa en Gran Bretaña, prensa en Australia, prensa en Irlanda, modelo de prensa anglosajón.

\begin{abstract}
Besides the language, the countries of Anglo-Saxon culture largely share a similar origin for their respective systems of the press and a democratic and entrepreneurial frame without identified interruptions. On the other hand, each country has followed a different evolution mainly marked by the relations between the State and the Press. From this angle, the United States has been the country less interventionist, followed by Britain. Ireland and Australia, by contrast, have implemented laws and regulations designed to combat such diverse areas as libel, slander, the publication of official secrets or business concentration. Without doubt, the new challenges posed by digital media and the global economic crisis are forcing a review of these four national models.
\end{abstract}

State Policies in the Anglo-Saxon model of Press

Keywords: U.S. Media, Press in Britain, Press in Australia, Press in Ireland, Anglo-Saxon press model.

\section{Referencia normalizada}

AGUADO GUADALUPE, Guadalupe; SANMARTÍ ROSET, Josep María; MAGALLÓN ROSA, Raúl (2011): "Políticas de Estado en el modelo de prensa anglosajón". Estudios sobre el mensaje periodístico. Vol. 17, núm. 2, págs.: 285-302. Madrid, Servicio de Publicaciones de la Universidad Complutense.

Sumario: 1. Introducción: rasgos comunes y diferenciales en el modelo anglosajón. 2. El sistema británico liberal y de negocio. 2.1. Un marco de libertad para la industria periodística. 2.2. Un sistema de control fiscal. 3. Estados Unidos: prensa libre sin intervención gubernamental. 3.1. La posición nortea-

${ }^{1}$ Esta investigación es fruto de estancias de investigación en el Institute of Communication Studies de la Universidad de Leeds y el Department of Communication de la Universidad de California, San Diego. 
mericana a favor del free flow. 3.2. Wall Street y la lógica de libre mercado. 4. Irlanda: libertad de expresión, un derecho con límites. 4.1. La importancia del orden público y moral. 4.2. Privacidad, difamación y blasfemia. 4.3. Límites al capital extranjero. 5. Australia: el continuismo del modelo anglosajón. 5.1. Regulaciones en un modelo de tradición democrática ininterrumpida. 5.2. Las leyes restrictivas: difamación y secretos oficiales. 5.3. Medidas anticoncentración. 6. Perspectivas de futuro. 7. Conclusiones. 8. Referencias bibliográficas.

\section{Introducción: rasgos comunes y diferenciales en el modelo anglosajón}

La definición de un modelo de prensa anglosajón, que Daniel HaLLIN y Paolo MANCINI denominan "del Atlántico Norte o Liberal", se basa en una procedencia común para varios países de cultura inglesa y una evolución compartida en varios aspectos fundamentales. Estos rasgos muy cercanos pueden ser hallados en los cuatro países analizados en este artículo (Reino Unido, EEUU, Irlanda y Australia), pero también en otros de la misma esfera, como Canadá. El punto de partida se sitúa en las experiencias revolucionarias en Inglaterra entre 1628 y 1688, cuando se formulan una serie de principios indispensables para la libertad de prensa (Hobbes, Milton, Locke, etc.) y se producen distintos experimentos empresariales y técnicos que tendrán su continuidad en el siglo XVIII y XIX. Un segundo referente es la revolución e independencia de los EEUU (1765-1776) que culmina con la Constitución de 1787. La doctrina emanada de estos dos procesos revolucionarios, reforzados sin duda por las aportaciones de la Ilustración del siglo XVIII, impregnará los sistemas informativos de los cuatro países, aunque tarde o temprano también inspirará los de todas las democracias. Se trata, pues, de un marco liberal-democrático, que se aplica en EEUU desde el principio y abiertamente en Gran Bretaña desde mediados del siglo XIX.

El otro elemento clave es la continuidad democrática y empresarial en estos países, al contrario de lo sucedido en la Europa continental o en otras zonas, como América Latina, sujetas a oscilaciones e interrupciones provocadas por regímenes totalitarios o dictaduras que suspendían los valores democráticos y desbarataban los entramados empresariales. El caso de España entre 1936 y 1976 es quizá el más paradigmático. Este funcionamiento democrático-liberal y esta tradición de negocio ininterrumpida aparecen claramente en los componentes del modelo anglosajón, si bien es cierto que con modulaciones distintas, de acuerdo con la evolución histórica de cada Estado y de sus empresas. El impacto de las dos guerras mundiales, por poner un ejemplo.

Ahora bien, esta misma evolución es la que proporciona a cada país un sistema de prensa propio, caracterizado en primer lugar por el papel del Estado en el desarrollo de la prensa, de tal manera que en los aspectos concretos aparecen diferencias importantes, casi tan importantes como las que se pueden observar con los países adscritos a otros modelos.

Así pues, el objetivo de este estudio es analizar cómo inciden las relaciones PrensaEstado en el desarrollo de las estrategias empresariales de las empresas informativas de EEUU, Reino Unido, Irlanda y Gran Bretaña. Para ello se examinan las diferentes medidas legislativas en lo relativo a tres aspectos: la censura, los impuestos y los límites a la concentración, sin olvidar otros factores de índole política, territorial, social y cultural que pueden incidir en la configuración de modelos según los territorios escogidos. Para entender la situación actual al respecto se realiza un estudio histórico y 
se indaga en las situaciones, decisiones y medidas que a lo largo de los años han dado lugar a la realidad presente según las diferentes áreas geográficas objeto de estudio. Es verdad que el modelo de prensa anglosajón se caracteriza por establecer su punto de inicio común en la inhibición de los poderes públicos (SANMARTí, AgUADO y MAGALLÓN: 2010), la cual se desarrolló en concordancia con la tradición norteamericana a partir de la Primera Enmienda a la Constitución de los EEUU (15 Diciembre 1791). Esta Primera Enmienda señala que "el Congreso no hará ley alguna con respecto a la adopción de una religión o prohibiendo el libre ejercicio de dichas actividades; o que coarte la libertad de expresión o de la prensa, o el derecho del pueblo para reunirse pacíficamente, y para solicitar al gobierno la reparación de agravios".

De este modo, se pretende abordar aquí la pertinencia de hablar de modelos informativos definidos por zonas territoriales, que den lugar a claras diferencias en atención a segmentaciones geográficas. De la misma forma, resulta necesario repasar las causas históricas, normativas y comerciales que han contribuido a dicha configuración y evaluar cómo las diversas políticas de ayuda y de gravámenes repercuten en las cabeceras a la hora de desarrollar iniciativas empresariales, afrontar riesgos y diseñar estrategias de posicionamiento en el mercado; o si en realidad lo que hacen es contribuir a una parálisis en la toma de decisiones.

\section{El sistema británico liberal y de negocio}

Una vez resueltas las tensiones derivadas de la Guerra Civil del siglo XVII, Gran Bretaña se adentró en un modelo caracterizado por una relativa libertad de expresión, reconocida para el Parlamento en el Bill of Rights de 1689, pero castigada mediante una red de impuestos y tasas que impidieron una prensa de masas pionera. A mediados del siglo XIX estos impuestos fueron desapareciendo, dejando paso a un sistema parecido al norteamericano con libertad de empresa y de expresión, y sometido simplemente a las leyes ordinarias y a las oscilaciones mercantiles.

La prensa de negocio surgió en Gran Bretaña a finales del siglo XVIII y fueron apareciendo empresarios con una nueva mentalidad, que modernizaron sus empresas, redujeron costos y aumentaron la capacidad productiva con un fin lucrativo. Por esto, hacia 1830 la prensa inglesa era un sector muy activo, dirigido fundamentalmente a las elites sociales de la época victoriana. Sin embargo, como altavoz político y agitador representó un papel menor que en el Continente, mucho más turbulento por ser el escenario de distintos procesos revolucionarios. Por el contrario, la prensa obrera se mostró lógicamente más radical. La supresión de las tasas a partir de 1853 alentó el crecimiento de una prensa barata y competitiva y por ende popular, con las particularidades de los periódicos locales y regionales.

\subsection{Un marco de libertad para la industria periodística}

En el caso de Inglaterra a finales del siglo XVII el derecho a la libertad de expresión se fue imponiendo, aunque con importantes reticencias, en los pactos constitucionales, en las leyes y en la jurisprudencia, mientras que las medidas coercitivas fueron desplazadas hacia los impuestos y las tasas, sin obviar ciertas actuaciones políticas que significaban una censura en la práctica. Tal y como relata Nieves SALDAÑA, "en efecto, la 
derogación del sistema de censura inglés en 1695 provocó que el libelo sedicioso constituyera el principal mecanismo legal con que contaba la Corona británica para restringir la crítica política, llegando a ser a partir del siglo XVIII vehículo paradigmático de control de la opinión pública a ambos lados del Atlántico" (SALDAÑA, 2004: web).

Fue en Inglaterra, donde se aprobó en 1792 la Libel Act, la primera ley de prensa de inspiración burguesa y en la práctica represiva, como reacción a la Revolución Francesa y al ascenso de la prensa popular. Con todo, esta ley, reformada en 1843, ya precisaba las acusaciones por las que los periodistas podían ser conducidos ante un jurado. En 1819 hubo además una importante reducción de cabeceras a causa de las Six Acts, destinadas oficialmente a prevenir atentados terroristas y de paso perseguir las publicaciones más radicales. Pero a finales del siglo XIX se impuso la Common Law o derecho común, que trasladaba definitivamente a la justicia ordinaria la persecución de los delitos de prensa y el modelo inglés se vio libre de estas limitaciones, excepto durante las dos guerras mundiales y en algún asunto concreto, como el terrorismo en Irlanda del Norte en la segunda mitad del siglo XX.

Uno de los factores que han marcado el devenir de la prensa británica ha sido su peculiar relación con el poder. La tradición de los periódicos con propiedad política ha sido mucho más débil que en el Continente. No ha habido subsidios, ni directamente a través de los partidos políticos o de individuos afiliados, o indirectamente desde el Estado, que hayan sostenido una prensa política, como en el resto de Europa. Como consecuencia, entre 1945 y 1995 la prensa fue cada vez menos predecible y manejable para los partidos, y por lo tanto, menos satisfactoria para ellos.

Junto a un sistema defensor de la libertad de prensa, otra de las claves de la prensa inglesa ha sido la industrialización del sector. En este sentido, como señala Macu ÁLVAREZ, la denominada nueva tecnología aplicable a la prensa llegó al Reino Unido coincidiendo con una falta crónica de beneficios. La industria periodística estaba caracterizada por un adverso cash-flow, altos costes de producción y un bajo desarrollo potencial debido a la saturación del mercado y a los efectos de la recesión económica. Por ello, en 1977 se constituyó una Comisión Real -la tercera desde la Segunda Guerra Mundial- para someter a un profundo chequeo a la industria periodística. El análisis se planteó no como una cuestión de ingresos, sino de costos. Se hablaba de reducciones de mano de obra en más del 50\%, afectando a los departamentos de composición. Estas reducciones podrían propagarse hasta otras áreas productivas, consiguiendo un $30 \%$ de ahorro en salarios. Los estudios sobre la industria periodística británica, especialmente la de alcance nacional, hacían hincapié en la generosidad de sus niveles de empleo y los altos salarios que se habían aplicado a sus trabajadores. La nueva tecnología se convertía, por lo tanto, en un poderoso instrumento no sólo para reducir el volumen de los salarios, sino también para contrarrestar el poder de los sindicatos (ÁlLVAREZ, 1989: 113-120).

Todo ello ha dado como resultado un modelo de prensa en el que desde 1945 se dibujó claramente la distinción entre prensa de calidad y prensa popular, clasificación que llega hasta nuestros días pudiendo apreciarse las diferencias entre prensa de calidad, mercado medio y prensa popular (quality papers, middle market y populars). 


\subsection{Un sistema de control fiscal}

Cuando a principios del siglo XIX se incrementaron los impuestos sobre los periódicos británicos, la prensa inglesa se convirtió en una de las más caras del mundo, impidiendo una tirada global comparativamente mayor. Incapaces de pagar los altos impuestos exigidos por el Estado, las corrientes políticas progresistas y las incipientes acciones del movimiento obrero (utópicos, Trade Unions, cartistas, etc.) iniciaron el "movimiento de los intimbrados" y organizaron una prensa sin impuestos a partir de 1831 aunque ya en 1802, por ejemplo, comenzó a publicarse el Political Register de William Cobbett, un semanario político, ingenioso, independiente y crítico de cualquier situación que no favoreciese la libertad e independencia de los hombres.

La prensa radical (intimbrada) era popular, progresiva y obrera y evadía los impuestos estatales con una distribución propia y paralela. Esta resistencia tuvo una gran importancia, dado que obtuvieron los primeros éxitos contra las tasas y a la larga fueron los causantes de su desaparición. Por otra parte, resultó clave para la expansión del movimiento cartista y unionista y de la conciencia de clase, así como para la creación del primer mercado popular de prensa, poniendo en contacto a las masas obreras con publicaciones periódicas y seriadas. El gobierno lanzó entonces una contraofensiva aumentando las penas para quien leyera periódicos sin el sello oficial de correos, promoviendo una prensa barata dentro de la legalidad y de paso una sociedad para la "instrucción popular", recogiendo fondos que permitieron la edición del Penny Magazine, y empezando a reducir las tasas en 1833 para iniciar así el camino de su supresión. Esta reacción del gobierno repercutió favorablemente en la normalización del mercado inglés, pues para 1837 la prensa radical o había aceptado las tasas rebajadas o había desaparecido.

La supresión del impuesto público sobre los periódicos entre 1853 y 1861 provocó una reducción global del precio y un aumento de su circulación, instaurando la llamada penny press o prensa de masas al alcance de las clases populares. A medida que aumentaba la circulación creció la publicidad, proporcionando a los editores una fuente importante de financiación además de la procedente de las ventas. Todas estas circunstancias desembocaron finalmente a principios del siglo XX en la adopción generalizada del periódico a medio penique en Gran Bretaña.

Tras el paréntesis de la II Guerra Mundial, la prensa se desarrolló en el Reino Unido de acuerdo a un modelo de Estado liberal. Por otra parte, y frente a los países euromediterráneos que entienden el papel del Estado como garante del pluralismo (Aguado, Sanmartí y Magallón, 2009: Web), "en el Reino Unido, la libertad de prensa no está constitucionalmente protegida y tampoco lo están las libertades públicas de expresión, en comparación con otros países" (SARIKAKIS, 2004: 83). En este país el Estado regula la radio y la televisión, pero no la prensa y, por esta razón, sólo la BBC (nacida en 1926) es entendida como un servicio público frente a la prensa. Son destacables asimismo las diferencias en la regulación de publicaciones y medios de comunicación. Así, la venta de periódicos podía estar sujeta a la aprobación de la Monopolies and Mergers Comisión, mientras que la de libros, no. Además, hasta 1990 los medios impresos estaban sujetos a la Obscene Publication Act, que no afectaba a los medios audiovisuales. 


\section{Estados Unidos: prensa libre sin intervención gubernamental}

A lo largo de los siglos XVII y XVIII, la influencia del modelo británico de prensa fue decisiva en las colonias americanas, pero adoptando rasgos propios. Como señala SALDAÑA, "la proliferación de material impreso en la Europa de los siglos XVI y XVII supuso el establecimiento de un férreo control estatal sobre su producción y difusión de carácter preventivo y posteriormente represivo, paradigmáticamente reflejado en la Inglaterra de los siglos XVI y XVII. Férreo control que traspasaría las fronteras oceánicas para arribar a las tierras colonizadas de Norteamérica, donde la conquista de la libertad de expresión tendría que librar la más feroz batalla para superar la aplicación del libelo sedicioso vigente en el Common Law" (SALDAÑA, 2004-2005: web). Un hito en la lucha de Estados Unidos por la libertad de información, fue la batalla desencadenada a causa de la Stamp Act británica (1765), ley que gravaba todos los documentos legales e impresos.

La fusión de las teorías iusnaturalistas y del contrato social propias de la Ilustración produjo una serie de declaraciones estatales de derechos básicos que culminaron en la Constitución de 1787. Ésta no menciona el de libertad de prensa, pero en 1791 el Congreso y el Senado aceptaron la inclusión en forma de enmiendas de una Declaración de Derechos (Bill of Rights), la primera de las cuales establece que "Congress shall make no law respecting an establishment of religion, or prohibiting the free exercise thereof; or abridging the freedom of speech, or of the press; or the right of the people peaceably to assemble, and to petition the Government for a redress of grievances". A pesar de ello, a causa de un conflicto naval con Francia en 1798 el Congreso aprobó la Sedition Act, que originó una serie de medidas represivas hasta que decayó en 1801 al terminar su mandato el presidente John Adams. En el siglo XX, y durante la Primera Guerra Mundial se aprobó la Espionage Act (1917), endurecida por una segunda Sedition Act (1918), que provocó cientos de procesos contra periódicos y periodistas hasta 1920. (Aunque enmendada, la Espionage Act sigue vigente y su aplicación fue solicitada en 2010 para el fundador de Wikileaks, Julian Assange.) Durante la Segunda Guerra Mundial también se aplicaron medidas represivas contra la libertad de prensa, si bien en menor medida.

La rotundidad de la Primera Enmienda no evitó fuertes y largos debates de contenido constitucional, político, parlamentario o legal (SALDAÑA, 2006: web), pero en términos generales se la ha considerado la base jurídica y uno de los pilares que hizo posible la expansión de periódicos en Estados Unidos a lo largo de los siglos XIX y XX y que garantizó el derecho individual a la libertad de expresión y de prensa. A partir de 1920 se unió a ello la presión por la nacionalización del Bill of Rights, que hizo que, a consecuencia de la Guerra de Secesión, el Tribunal Supremo aceptara la Enmienda Catorce $(1868)^{2}$ y protegiera la libertad de expresión y de prensa estable-

\footnotetext{
${ }^{2 " A}$ "All persons born or naturalized in the United States, and subject to the jurisdiction thereof, are citizens of the United States and of the State wherein they reside. No State shall make or enforce any law which shall abridge the privileges or immunities of citizens of the United States; nor shall any State deprive any person of life, liberty, or property, without due process of law; nor deny to any person within its jurisdiction the equal protection of the laws".
} 
cida en la Primera Enmienda. De manera que, como señala Mauricio BeltrÁn "la libertad de expresión, en general, fue protegida antes que los gobiernos reconocieran una participación democrática absoluta" (BELTRÁN, 2005: 116)

En todo caso, a lo largo de este proceso Estados Unidos se colocó a la vanguardia en la defensa de la libertad de expresión y de prensa en el mundo, quedando protegidos los ciudadanos estadounidenses por el bloque constitucional frente cualquier arbitrariedad impositiva del poder político. Es destacable, pues, el hecho de que realmente no existe una ley de prensa federal en los Estados Unidos, pues la autoridad moral de la Primera Enmienda fue capaz de establecer el principio sagrado del respeto insoslayable al valor de la expresión individual y de la libertad de prensa. Pero si bien es cierto que no existen leyes referenciales concretas acerca de la libertad de expresión, sí que tenemos una notable variedad de dictámenes del Tribunal Supremo y de leyes estatales, que han servido para reiterar y consolidar la importancia de la Primera Enmienda, como sostén de la libertad de expresión dentro de un régimen de derecho.

Tal vez la más importante entre estas sentencias es la del juez del Tribunal Supremo, Hugo Black, cuando en 1971 ante el caso de los Documentos del Pentágono, que el presidente Richard Nixon no quería que se publicaran, sentenció que "el poder del gobierno de censurar a la prensa fue abolido para que la prensa tenga siempre libertad de censurar al gobierno" (MÜLLER, 2006: Web)

\subsection{La posición norteamericana a favor del free flow}

En el ámbito de la comunicación Estados Unidos ha propugnado un marco internacional político y jurídico favorable a la libre circulación de los flujos informativos, lo que se conoce como la posición norteamericana a favor del free flow. Como dice Ferdinand TERROU "esta doctrina suponía, en el plano internacional, la supresión de todos los obstáculos político-jurídicos que la división entre Estados podría oponer al poder de las empresas de información para constituirse y funcionar según sus propios criterios, y para investigar y distribuir por doquier y sin trabas elementos de información (noticias y opiniones)" (TERROU, 1951: 163). En la práctica se ha defendido una empresa de prensa libre, sin intervención gubernamental alguna, pluralismo en las fuentes informativas, etc.

La postura norteamericana se articuló alrededor de las nuevas realidades económicas y tecnológicas que se fueron configurando después de la II Guerra Mundial. Es interesante destacar que la teoría del free flow, formulada por el director de la Associated Press (AP) Kent Cooper y que sirvió para combatir el monopolio europeo, fue un antecedente ideológico de la posición que mostraron los Estados Unidos para oponerse a los planteamientos del Tercer Mundo y de la UNESCO a partir de 1975, recogidos en el NOMINC y el Informe MacBride. Es decir, libertad contra "cartel" o contra el intento de control estatal de la información promovido por los países no alineados. En ambos casos, la ofensiva estuvo centrada en unas agencias (AP y UPI), que son empresas privadas y cooperativas de diarios y que no tienen el carácter de públicas o parapúblicas de la mayoría de las agencias europeas (AFP, EFE, DPA, ANSA). Andreu CLARET recuerda que "la defensa del free flow no era una cuestión puramente 
corporativa. Afectaba los intereses estratégicos de los Estados Unidos en una época en que se iniciaba la Guerra Fría" (ClARET, 1994: Web). Más aún, en 1945 el Secretario de Estado John F. Dulles lo dejó claro al afirmar que "si me obligasen a escoger un único principio de política exterior escogería la libre circulación de la información" (GIFREU, 1986).

\subsection{Wall Street y la lógica de libre mercado}

En la década de 1970, años en los que se produce en la UNESCO lo que se conoce como "giro crítico", Estados Unidos luchó denodadamente contra el establecimiento de unas Políticas de Comunicación (PAC) aplicables a los países que conformaban la organización. Su argumento más utilizado fue que tales políticas constituían un intento de estatalización de la información, y por tanto un revés para la libertad de información.

Esta misma lógica en las políticas comunicativas ya se observó durante las administraciones de John F. Kennedy (1960-1963) y James Carter (1977-1981), que en este aspecto enlazaron a la perfección con las actuaciones llevadas a cabo años después por Ronald Reagan (1981-1989) y George H. W. Bush (1989-1993). Es decir que el cambio de signo del partido político en el poder no ha significado en absoluto una transformación del camino marcado desde 1945 por el presidente Harry Truman. De hecho, los años 80 fueron una década clave para el desarrollo de la industria de medios de comunicación estadounidenses. Gracias al proceso desregulador estimulado por la Administración Reagan, que culminó con la aprobación de la Ley de Telecomunicaciones de 1996 por el presidente Bill Clinton (1993-2001), las empresas multimedia se convirtieron en corporaciones gigantescas, en las que los periódicos tenían una importancia relativa. La eliminación de la mayoría de las restricciones existentes con respecto a la propiedad de medios favoreció el crecimiento exponencial de los grupos y el aumento de la concentración de medios en EE.UU.

Sin embargo, el mismo modelo económico que potenció la industria periodística norteamericana provocó una de sus mayores crisis desde los años 90. Los propios norteamericanos lo han reconocido al sostener que "la industria periodística se suicidó en aras de Wall Street y de la misma lógica del libre mercado que ha resultado funesta para tantas industrias estadounidenses. El pecado original de los periódicos estadounidenses está en primer lugar, sin duda, en Wall Street", declaró David Simon, el expropietario del Baltimore Sun (SAHAGúN, 2009: 17).

En efecto, en un debate celebrado el 6 de mayo de 2009 en la Subcomisión de Comunicaciones, Tecnología e Internet del Senado se habló de reformar el marco económico y empresarial y de regulaciones legales para un bien público. "Wall Street y la lógica de libre mercado, habiendo sido las fuerzas destructoras del periodismo en las últimas décadas, no van a ser de repente su salvación. El capitalismo sin control nunca es la respuesta cuando está en juego un bien público, una misión pública. Si algo nos ha enseñado el último cuarto de siglo es que el capitalismo de libre mercado, sin imperativos sociales ni supervisión responsable de los reguladores, puede producir bienes y servicios duraderos y grandes beneficios, pero poco valor social", sostuvo David Simon (SAHAGÚN, 2009: 19). 
Precisamente unas semanas antes el senador demócrata Benjamín Cardin había presentado un proyecto de ley, la Newspaper Revitalization Act, coincidente con otro de la congresista republicana Carolyn Maloney, que permitía que las empresas periodísticas que lo desearan pasaran a ser controladas por fundaciones a fin de obtener beneficios fiscales siempre que dejaran de tener afán de lucro ${ }^{3}$. También en la American Society of News Editors se ha planteado en algún momento la posibilidad de un programa gubernamental de rescate de los periódicos en crisis ${ }^{4}$. Esta preocupación se reflejó en el Joint Economic Comittee de la Cámara de Representantes que el 24 de Septiembre de 2009 debatió la situación de los periódicos en términos parecidos al Senado 5 .

\section{Irlanda: libertad de expresión, un derecho con límites}

El desarrollo de los medios de comunicación irlandeses se ha visto muy marcado por la evolución de los ingleses, debido a los estrechos lazos históricos, políticos y económicos entre los dos países. Desde su creación en el siglo XVII, los periódicos en Irlanda han sido ciertamente entidades privadas, sobre todo comerciales, establecidos principalmente por hombres de negocios con intención de lucro y con el objetivo de difundir información, aunque la mayoría de ellos demostró fuertes inclinaciones ideológicas y políticas en sus contenidos (HoRGAN, 2001). Debido a las dimensiones relativamente pequeñas de la economía irlandesa y a su posición periférica respecto de la Unión Europea, así como a su relación con el mundo anglosajón, no es sorprendente que las cuestiones sobre los medios de comunicación y sobre la identidad cultural aparezcan tan tarde en la agenda de investigación irlandesa (CORCORAN, 1997).

Además de las contundentes incursiones y ofertas de adquisición por parte de inversores extranjeros, entre las cuestiones principales que han enfrentado a la industria de los medios irlandeses desde la mitad de la década de los 80 se encuentra la competencia con los periódicos del Reino Unido y los centros de radiodifusión, así como la preocupación por las leyes de difamación.

\subsection{La importancia del orden público y moral}

La Constitución irlandesa de 1937 ampara el derecho a la libertad de expresión, del que se deriva la libertad de prensa. No obstante, no se trata de un derecho sin límites. Al contrario, es un objeto de determinadas restricciones relacionadas con el orden público y la moral. Importantes en este sentido han sido las relaciones entre el Estado y la Iglesia Católica, pues a pesar de la separación oficial de ambas instituciones, al menos hasta los años setenta afirmaban la existencia de una identidad nacional irlandesa basada en las enseñanzas católicas morales y sociales. Eamon de Varela (18821975), destacado líder del movimiento nacionalista Fianna Fail y de la independencia,

${ }^{3}$ Senado de los EEUU. Disponible en http://cardin.senate.gov/pdfs/newspaperbill.pdf (consultado el 18/02/2011)

${ }^{4}$ American Society of News Editors. Disponible en: www.asne.org (Consultado el 18/02/2011)

${ }^{5}$ Newspaper Association of America. Disponible en: http://www.naa.org/Public-Policy.aspx (Consultado el 18/02/2011) 
y presidente de la República, contemplaba a Irlanda como una nación católica. Para asegurar la continuidad de este catolicismo irlandés, el gobierno de Eamon de Valera prohibió la venta e importación de anticonceptivos artificiales, estableció una regulación para las salas de fiesta y tasó con impuestos los periódicos extranjeros (DILLON, 2006: 72-73).

La Constitución irlandesa establece que la educación de la opinión pública es una cuestión de importancia para el bien común, por lo que el Estado se esforzará por garantizar que en el caso de los órganos de opinión pública como la prensa, al tiempo que se preserve su correspondiente libertad de expresión, incluída la crítica gubernamental, no se puedan valer de la misma para socavar el orden público, las buenas costumbre o la autoridad del Estado.

Por otra parte, el artículo 40.6.1 de la Constitución, que garantiza a todos los ciudadanos el derecho a expresar libremente sus convicciones y opiniones, constituye la base de la libertad de prensa en Irlanda. Esta libertad es atenuada, sin embargo, por una disposición adicional, que aunque reconoce la necesidad de preservar la libertad de expresión que le corresponde, afirma que la publicación o emisión de materiales blasfemos, sediciosos o indecentes es un delito que se castiga de conformidad con la ley. No se puede olvidar que estamos ante un país marcado por una fuerte tradición censora, donde la Junta de Censura desempeñaba un papel implacable y podía prohibir la venta y distribución de todas las publicaciones que se considerasen indecentes, es decir incitadoras a la inmoralidad sexual o al vicio.

\subsection{Privacidad, difamación y blasfemia}

A pesar de que la Constitución irlandesa no recoge el principio de privacidad, la Corte Suprema ha establecido que el derecho de privacidad es uno de los derechos personales fundamentales de los ciudadanos que se derivan de la naturaleza cristiana y democrática del Estado. De acuerdo con la legislación, la difamación a través de una publicación es definida como una declaración falsa sobre una persona que propicia un deterioro en la estimación del individuo. Más concretamente, la Ley de Difamación de 1961 no requiere que el demandante pruebe qué medio ha sido negligente, ni que aporte pruebas de haber sido perjudicado personalmente o profesionalmente. Sólo tiene que demostrar que las palabras ofensivas referidas a él fueron publicadas por el medio, quedando en manos del editor demostrar que la información es cierta.

Teniendo en cuenta que en el caso de Irlanda no se cuenta ni con consejos de prensa, ni con la figura del defensor del lector, oyente o telespectador, se explica que los conflictos de los ciudadanos con los medios de comunicación se resuelvan a través de los tribunales. $\mathrm{Y}$ en dicho contexto las demandas contra la privacidad y la difamación son lógicamente frecuentes, especialmente en el caso de los funcionarios públicos, que pueden demandar por difamación a expensas del Estado. Si pierden no deben nada al Estado y si ganan se quedan con la indemnización. Dicha situación provoca una alta vulnerabilidad en los medios de comunicación, que se enfrentan a situaciones conducentes a pactos al margen de los tribunales para no hacer frente a los gastos de un juicio y a las graves sentencias que se dictan. Téngase en cuenta que las demandas por difamación en Irlanda representan un coste de millones de euros anuales para los periódicos. Por esta razón en 
las plantillas de los periódicos se cuenta con abogados que asesoran con la máxima "en caso de duda dejarlo fuera". La situación llega a tal extremo que hay casos en que los editores se encuentran con el rechazo de distribuidores y puntos de venta frente a la publicación, para evitar ser demandados también por difamación.

Naturalmente así se hace difícil trabajar en periodismo de investigación, lo cual ha llevado a la Prensa Nacional de Irlanda (NNI) a plantear cambios en las leyes de difamación, a cambio de implantar sistemas de autorregulación, debiendo contemplarse los tribunales como última instancia. En este sentido, la NNI es partidaria de un código ético que sería de aplicación por un ombudsman o por un Consejo de Prensa. En otros casos se ponen los ojos en el Tribunal Europeo de Derechos Humanos de Estrasburgo, por considerar que el excesivo celo en impedir la difamación puede afectar a la libertad de expresión.

En 2010 se aprobó la reforma de la Ley de Difamación de 1961, contemplándose la blasfemia como un delito punible con una multa de hasta 25.000 euros, al tiempo que queda definida como "el uso de términos abusivos o insultos sobre asuntos considerados sagrados por cualquier religión y que causen ultraje a un número sustancial de seguidores de esa fe". La reforma ha sido calificada por algunos de anacrónica y un intento de imponer la religión por encima de la libertad de expresión. No ha de olvidarse que la blasfemia ya era un aspecto contemplado en la Constitución irlandesa. La diferencia radica en que según la Constitución, la blasfemia será castigada según la ley, pero el concepto quedaba definido de una forma tan difusa que impedía la práctica al respecto. Sin embargo, ahora ese vacío legal ha quedado resuelto estableciéndose un alcance más concreto de blasfemia que da lugar a la aplicación de la ley. Frente a las críticas recogidas, el ministro de Justicia se ha defendido explicando que esta reforma no implica un endurecimiento de las penas, sino simplemente definir con precisión un aspecto que recoge la Constitución.

La regulación del delito de blasfemia ha tenido sus consecuencias en el retroceso que ha sufrido la posición de Irlanda en los índices de libertad de prensa de Reporteros Sin Fronteras (RSF) correspondiente a 2010. Desde esta organización se ha condenado enérgicamente la ley por considerar que "ofrece una base legal a los extremistas religiosos de todo tipo. Lo que les permite utilizar la fuerza de la ley para imponer sus puntos de vista".

La presión de la Prensa Nacional de Irlanda (NNI), fundada en 1985, y la Unión Nacional de Periodistas (NJU) obligó al gobierno a establecer la Comisión de Industria del Periódico en septiembre de 1995, con el fin de investigar y ofrecer soluciones a estas cuestiones. La otra novedad interesante en la década de 1990 fue la promulgación de la Ley de Libertad de Información en abril de 1996, que ofreció a los periodistas un nuevo marco para la realización de reportajes de investigación.

La historia de la censura en Irlanda es también la historia de la reducción de la censura. Así, frente a la antigua Ley de Secretos Oficiales, en la que se establecía que todos los documentos del gobierno son secretos a menos que se especifique lo contrario, con la Ley de Libertad de Información la mayoría de los documentos del gobierno, a excepción de los relativos a aspectos legislativos o referentes a temas especialmente sensibles, están disponibles bajo petición. 


\subsection{Límites al capital extranjero}

A diferencia de los medios audiovisuales, la prensa irlandesa no ha sido objeto todavía de una ley específica, si bien existe un gran número de reglamentos que afectan a la misma, como es el caso de la Official Secrets Act. No hay tampoco un consejo de prensa, ni se ha regulado el derecho de réplica, aunque algunos periódicos han establecido por su cuenta sus respectivos newspaper ombudsmen como un medio de atender las quejas de los lectores y de evitar pleitos costosos en los juzgados.

En cambio, la formación de monopolios en la industria periodística es un aspecto que sí ha sido regulado por una legislación concreta. Por ella, se capacita al Ministerio de Industria y Comercio para prohibir cualquier cambio en el control de la propiedad, siempre que éste afecte a más del $30 \%$ de las acciones. Asimismo, las inversiones de capital extranjero en la prensa irlandesa están limitadas de hecho, por más que la ley no establezca ninguna restricción explícitamente (GARRIDO DONAIRE, 1994: 257).

$\mathrm{Al}$ igual que en el resto del Continente, en Irlanda la prensa ha experimentado un proceso de concentración de la propiedad, lo que llevó a la creación de la Comisión de la Industria Periodística (BARRET, 2000). Sin embargo, la oposición a los medios extranjeros en Irlanda no proviene del gobierno, sino de los propios editores irlandeses, que se quejan de la competencia desleal que para ellos suponen las empresas de medios británicos. Ello se debe a que los editores británicos pueden vender sus ejemplares en Irlanda a un precio inferior al de los medios irlandeses, ya que estos últimos han de afrontar un IVA del 12,5\%. En opinión de los editores irlandeses esto conduce a una situación en la que las cabeceras británicas se están haciendo con una importante parte del mercado tanto de diarios como de dominicales. La competencia se da no sólo a nivel de cabeceras, sino también de propiedad empresarial en un mercado en el que no existe límite formal a la propiedad extranjera en medios de comunicación irlandeses.

\section{Australia: el continuismo del modelo anglosajón}

Hasta bien entrado el siglo XX Australia dispuso de un sistema de prensa similar al británico, aunque con especificidades propias provocadas por las dimensiones geográficas del país, la dispersión de la población, el alejamiento de los grandes núcleos europeos, americanos e incluso asiáticos, o la complejidad político-institucional. Las dos guerras mundiales, sin embargo, significaron un giro importante en la política de medios. Al contrario que otros países del ámbito anglosajón, Australia vivió episodios de censura administrativa y las dos guerras agravaron esta situación, relacionada tanto con el transcurso de las operaciones bélicas, como con el debate sobre la identidad australiana, la construcción de la democracia nacional y los valores conservadores.

En términos generales el sistema de prensa australiano ha mantenido el continuismo propio del modelo anglosajón, tanto en su vertiente empresarial como democrática, dado que ambas han vivido una evolución sostenida y regular. Por otra parte, a finales del siglo XIX y principios del XX, los periódicos adquirieron el papel de grupo de presión, movidos por la defensa de los intereses zonales y sectoriales, por su 
oposición a la administración británica, a la preeminencia de las grandes ciudades y a la de la oligarquía terrateniente.

La dinámica empresarial hizo que tras la I Guerra Mundial se intensificara la concentración de cabeceras y la competencia entre ellas, de manera que el número de periódicos fue disminuyendo y aumentaron los enfrentamientos. Por lo general eran muy vulnerables a la manipulación comercial, hecho que se tradujo en la creación de la figura del Managing Editor, encargado de primar los intereses comerciales por encima de los profesionales, de acuerdo con la pujante experiencia norteamericana. Apareció de este modo un sistema de prensa en el que los editores estaban más atentos a sus intereses y a la autocensura que a la construcción de la democracia australiana, dando lugar a una prensa de entretenimiento más que de información (GIVEN, 2002: 253).

Entre 1900 y 1920 las políticas comunicativas se centraron en el "transporte de la comunicación", de tal manera que las tecnologías fueron cada vez más decisivas en un país caracterizado por las enormes distancias geográficas y la dispersión de su población. Poco a poco se convirtieron en el mejor símbolo del progreso nacional y de la lucha contra el aislacionismo hacia Europa, con lo que el debate alrededor de los medios adquirió un trasfondo esencialmente pragmático (GREENLAND, 1950: 222).

\subsection{Regulaciones en un modelo de tradición democrática ininterrumpida}

Al seguir la tradición británica de que sea la legislación ordinaria la encargada de los asuntos relativos a libertad de prensa, los tribunales australianos se rigen por los tratados internacionales, como la Declaración Universal de Derechos Humanos (1948) o los Pactos Internacionales de Derechos Humanos (1966), a pesar de que su aplicación requiere leyes específicas. Por otro lado, como es normal se aplican las leyes indirectamente relacionadas con los medios (fiscalidad, empresas, comercio, etc.), o más genéricas, como la de rebeldía. No existe, por lo tanto, una ley federal para la prensa, pero cinco Estados disponen de una Ley de Prensa e Imprenta propia, destinada a establecer distintas medidas administrativas como el registro de medios o la obligación de depositar un ejemplar en la biblioteca central correspondiente.

En diciembre de 1973 Colin Bednall, un influyente asesor del primer ministro Gough Whitlam, propuso la creación de una Australian Newspaper Commission, inspirada en la Broadcasting Commission, para examinar el sistema de propietarios de periódicos, radios, televisiones y las nuevas tecnologías que empezaban a surgir. De hecho, desde 1960 los expertos daban por perdida la batalla de la comunicación pública en Australia, ya que ningún gobierno se interesó por estructurar una política coherente en esta materia. Al fin y al cabo, como indican HALlin y MANCINI "la comercialización de los periódicos en los países del modelo liberal expulsó del sistema de medios de comunicación a varias formas de medios no comerciales" (HALlin y MANCINI, 2004). La liberalización económica a partir de 1975 y la expansión a partir de 1980 acrecentó el consumo de medios, pero la esfera pública se fue desregulando y la evolución mediática se volvió más competitiva aún.

De todos modos, en febrero de 1983 se firmó el Statement of Accord bajo el gobierno Hawke, que instituyó un mecanismo consultivo general para desarrollar políticas comunicativas más participativas y que fuera más allá de las infraestructuras. Además, los 
lazos con Gran Bretaña se iban aflojando en la medida en que ésta ingresó en la Comunidad Económica Europea (1973), se firmó la Australia Act (1986) y el Sureste asiático empezó a emerger con fuerza. En este ambiente se crearon varias comisiones y áreas de debate, pero los resultados fueron más bien escasos. Eso sí, sirvieron para que la comunicación se estructurara y se hiciera más centralizada. El gobierno Fraser llegó a crear un Ministerio de Comunicaciones muy inspirado en la Federal Commission of Communication (FCC) norteamericana, como regulador de los medios audiovisuales.

Las tres grandes limitaciones a la libertad de expresión en la historia de los medios de comunicación australianos, fueron la censura aplicada a libros y filmes en los años 1930 y 40, la concentración de propietarios y las leyes contra libelos y difamaciones (Osborne y Lewis, 1995). A lo largo de los siglos XIX y XX la evolución de la prensa australiana se inscribió en un marco democrático ininterrumpido, pero ello no fomentó los debates específicos, que en todo caso se desarrollaron en términos muy genéricos, poco matizados y sin conclusiones aceptables para todos. Por esta razón hubo que pensar en mecanismos reguladores. Finalmente los desafíos que se iban planteando a la libertad de expresión condujeron en 1976 a la fundación del Australian Press Council (APC) con la misión, entre otras, de investigar y resolver las denuncias y quejas contra los periódicos y sus empresas (www.presscouncil.org.au).

\subsection{Las leyes restrictivas: difamación y secretos oficiales}

En los años 1980 y 1990 hubo varios intentos para uniformizar la legislación sobre el delito de difamación, pero no tuvieron éxito y cada Estado lo regulaba por su lado. Tradicionalmente las denuncias y condenas por difamación habían constituido uno de los principales métodos perturbadores de la libertad de expresión, y finalmente el 1 de enero de 2006 entró en vigor una Defamation Act, que suavizaba las normas anteriores y ordenaba los procedimientos. En cambio, no está reglado ni el derecho de réplica, ni las ofensas hacia el Jefe de Estado, los miembros del gobierno o las instituciones. Por otro lado, en virtud de la Freedom of Information Act (FoI) de 1982 las autoridades pueden denegar el acceso de los medios a los documentos adscritos a distintas categorías, como la seguridad o la economía nacional, aunque de forma argumentada y con posibilidad de recurrir a los tribunales. Distintas reformas de la ley y sobre todo una sentencia (el caso McKinnon) endurecieron más esta situación.

El atentado del 11 de Septiembre de 2001 en EEUU provocó una serie de medidas gubernamentales antiterroristas que agravaron el secretismo de la Administración. La Australian Security Intelligence Organisation Act de 2003, la National Security Information (Criminal Proceedings) Act de 2004 y la National Security Information Legislation Act de 2005 llegaron al extremo de hacer celebrar las vistas judiciales a puerta cerrada si se entendía que tenían que atender información reservada. A todo esto se le añade, la Racial Hatred Act de 1995 que regula los delitos por discriminación racial, mientras que la ley ordinaria persigue la blasfemia, la obscenidad y los ataques a la moral (JONES and PUSEY: 2010). 


\subsection{Medidas anticoncentración}

A partir de 1954 se planteó una crisis en la prensa agravada con la aparición de la televisión (1956), que relanzó la polémica sobre los efectos de los medios. En estos momentos cuatro empresarios (sir Frank Parker, sir Warwick Fairfax, sir Rupert Murdoch y sir Philip Jones) poseían la mayoría de medios australianos. Este proceso se intensificó aún más, y hacia 1987 los periódicos metropolitanos estaban controlados por tres grandes grupos el Herald and Weekley Times Limited, el News Limited y el John Fairfax Group Pty Limited. Este mismo año el News Limited adquirió el Herald. Ello favoreció el nacimiento del grupo multimedia News Corporation dirigido por Rupert Murdoch, procedente de un conglomerado de periódicos construido desde 1921 por su padre, Keith Murdoch (WheElWRIGHT and BUCKLEY, 1987). La estrategia esencialmente mercantil de estos medios, apoyando alternativamente a los gobiernos que coincidían más con sus intereses, permitió su expansión y culminó en 1987 con la compra de la HWT. Murdoch se convirtió no sólo en el mayor empresario australiano, con los contrapesos del grupo Fairfax y del Consolidated Press, sino que en los años 60 se expandió por el Reino Unido y en los 70 por EEUU para construir uno de los mayores grupos mediáticos del mundo con un fuerte contenido conservador (BARRERA, 2004: 217).

A principios de los años 90 prosiguió el proceso de concentración, que se caracterizó por la disminución de periódicos nacionales a causa de las dificultades en la distribución, quedando The Australian y Australian Financial Review. Excepto Sidney y Melbourne ninguna otra capital disponía de más de un periódico diario. La News Limited pasó a controlar el 70 por ciento de la producción diaria metropolitana, mientras que el grupo Fairfax lo hacía con el 20 por ciento. Éste último aumentó su peso en 2007 al fusionarse con el grupo Rural Press e impulsó su expansión internacional. La evolución descrita obligó a reformar la legislación relativa a la propiedad de los medios, con el fin de asegurar como mínimo cinco grupos en el mercado federal y cuatro en los regionales. Los Estados también adoptaron medidas en el mismo sentido. Incluso la Australian Competition and Consumer Commission (ACCC) tuvo que intervenir para proteger la competencia empresarial de acuerdo con la Trade Practices Act de 1974, así como la Australian Communications and Media Authority (ACMA) en un marco reforzado de atribuciones.

\section{Perspectivas de futuro}

En el ámbito de las políticas de comunicación, Estados Unidos ha propugnado y seguirá propugnando un marco internacional político y jurídico favorable a la libre circulación de los flujos informativos. Sin duda, su tradicional defensa del free flow será determinante en el nuevo entorno de Internet, donde reduce por definición la jerarquización de la información a escala global. A nivel interno, el crecimiento exponencial de los grupos y el aumento de la concentración de medios seguirán planteando el problema de que estos medios se integran en grandes empresas con intereses en mercados completamente alejados de la comunicación. En semejante contexto no debería perderse de vista la máxima de David SIMON de que "el capitalismo sin control nunca es la respuesta cuando está en juego un bien público, una misión pública". 
Dicha misión pública y social de la prensa no puede verse condicionada por medidas que supongan un límite a la libertad de expresión como es el caso de Irlanda, donde anteponiendo principios como la defensa de la privacidad, considerada como un derecho derivado de la naturaleza cristiana y democrática del Estado, se limite la labor de editores, periodistas y distribuidores de prensa ante el miedo a las constantes demandas judiciales. Lo que sin duda, tal y como se ha visto en lo últimos indicadores internacionales, supone un lastre a la libertad de prensa, que ha de llevar a optar por medidas más conducentes a la autorregulación.

En lo que respecta a la prensa australiana, en el contexto actual, su perspectiva de internacionalización no puede establecerse a partir de un flujo informativo principalmente británico o estadounidense, sino que debe abrirse hacia Asia y convertirse en un referente en la creación y difusión de contenidos propios de la zona, sirviéndose de las ventajas de mercado que ofrece la lengua inglesa.

Frente al intervencionismo del Estado en la prensa ya sea a través de subvenciones o de medidas legislativas, que se da de una u otra manera en el modelo nórdico y euromediterráneo y la inhibición de los poderes públicos del modelo tradicional anglosajón, el modelo australiano necesita reorientar sus políticas de Estado hacia la cohesión territorial a través del desarrollo de la prensa. Si la radio sirvió en su momento de instrumento principal de cohesión social (por encima incluso de la televisión), la prensa digital puede recoger parte de las funciones de cohesión territorial que hasta este momento se le habían atribuido a la radio, además de servir de elemento dinamizador de las estructuras comunicativas del país.

\section{Conclusiones}

1. A diferencia de Irlanda y Australia, en el Reino Unido históricamente los límites a la libertad de expresión no se han establecido a través de una regulación legislativa, sino mediante estrategias coercitivas relacionadas con el aumento de impuestos y tasas.

2. Frente a la tradición del Reino Unido y los Estados Unidos, donde la prensa se ha desarrollado en un marco acorde a las leyes ordinarias y las oscilaciones de mercado, en el caso de Irlanda ha pesado mucho el excesivo celo de defensa de la privaidad como un derecho derivado de la naturaleza cristiana y democrática del Estado, dando lugar a continuas demandas judiciales que han condicionado el quehacer periodístico y las estrategias informativas.

3. A pesar del carácter inhibidor por parte del Estado que siempre ha querido representar el modelo anglosajón, tanto en Irlanda como en Australia, tradicionalmente la libertad de expresión ha sido objeto de determinadas restricciones relacionadas con el orden público, la difamación y los secretos oficiales.

4. Frente a la posición de Estados Unidos de defensa de la prensa sin intervención estatal, en el caso de Irlanda y Australia se ha puesto de manifiesto los requerimientos de dicha intervención en las leyes antimonopolio. Es más, en el caso irlandés los propios editores han manifestado su preocupación por las adquisiciones realizadas por inversores extranjeros, de manera que aunque no hay inguna restricción explícita a la inversión de capital extranjero está limitado de hecho. 
5. La autocensura ha sido una práctica típica en el modelo australiano. Australia carece de una ley específica para la prensa, pero ciertos desajustes de su modelo, en especial los efectos de la concentración de empresas, han obligado a buscar mecanismos reguladores y uniformizar la legislación federal con la de los Estados. Las leyes sobre la difamación o sobre secretos oficiales demuestran el dilema australiano entre la tradición no interventora y la necesidad de medidas correctoras ante los excesos empresariales y administrativos. Los medios públicos, sobre todo la radio, tienen como fin contrapesar la influencia de estos grupos dominantes.

6. Además de la lejanía geográfica, factores como la demografía (22 millones de personas) pueden permitir en Australia el desarrollo de unas políticas de ayudas y desarrollo empresarial imposibles en los países euromediterráneos o anglosajones que sirven tradicionalmente de modelo a imitar. Esto es posible por el carácter regulador que han tenido sus distintos gobiernos (a diferencia de Reino Unido y EEUU) desde la segunda mitad del siglo XX y que lo han convertido en un arquetipo con características propias. Estas ayudas deberían buscar la consolidación de nuevas iniciativas que consigan fomentar la convergencia en el ámbito de la prensa.

7. En el ámbito de las políticas de comunicación, Estados Unidos ha propugnado y seguirá propugnando un marco internacional político y jurídico favorable a la libre circulación de los flujos informativos, pero será su desarrollo tecnológico y la apuesta por una economía de la información digital la que le permita mantener una posición de privilegio a escala global.

\section{Referencias bibliográficas}

AGUADO, Guadalupe; SANMARTI, José María y MAGALLÓN, Raúl (2009): “The effect of the state on the evolution of print media in European Mediterranean countries", en International Journal of Communication: http://ijoc.org/ojs/ index.php/ijoc/article/view/560/352. [fecha de consulta: 23 de febrero de 2011]

ÁLVAREZ, Macu (1989): "La prensa nacional británica. Un modelo para el análisis", en Telos, $\mathrm{n}^{\circ}$ 18. Madrid, Fundación Telefónica, pp. 113-120.

AUSTRALIAN PRESS COUNCIL: www.presscouncil.org.au

BARRERA, Carlos (2004): Historia del Periodismo Universal. Barcelona, Ariel Comunicación.

BARRETT, Sean D. (2000): "Competitiveness and Contestability in the Irish Media Sector", en Trinity Economic Paper Series, n 2000/3.

BELTRÁN, Mauricio (2005): "Dos caminos diferentes para arribar al mismo lugar. La libertad de expresión en Canadá y Estados Unidos", en Estudios Socio-Jurídicos, $\mathrm{n}^{\mathrm{o}} 7$ (1), pp. 93-116.

CLARET, Andreu (1994): "Las nuevas reglas del juego. Agencias de prensa y relaciones Norte-Sur", en: http://www.xtec.cat/ cgarci38/ceta/sociedad/reglas.htm. [consultado el 6 de febrero de 2011]

CORCORAN, Farrel (1997): "La investigació sobre comunicació de masses a Europa: Irlanda", en : Análisi, $\mathrm{n}^{\circ}$ 21. Cerdanyola del Vallès, Universitat Autònoma de Barcelona, pp.199-210. 
DILLON, Michel (2006): "El catolicismo, política y cultura en la República de Irlanda", en Religión y política: Una perspectiva comparada. Ted Gerard Jelen y Clyde Wilcox (Eds). Ediciones Akal, pp. 72 y 73.

GARRIDO DONAIRE, Francisca (1994): "El periodismo en Gran Bretaña e Irlanda", en PIZARROSO QUINTERO, Alejandro (coord.): Historia de la Prensa. Madrid, Editorial Centro de Estudios Ramón Areces.

GIFREU, Josep (1986): El debate internacional de la comunicación. Barcelona, Ariel Comunicación.

GIVEN, Jock (2002): "Foreign ownership of media and telecommunications: an Australian story", en Media \& Arts Law Review, nº 7, p. 253.

GREENLAND, P. C. (1950): “Australia's Overseas Communication”, en Australian Journal of Public Administration, no 9, pp. 222-229.

HALLIN, Daniel y MANCINI, Paolo (2008): Sistemas mediáticos comparados. Barcelona, Editorial Hacer.

HORGAN, John (2001) Irish Media: A critical history since 1922. London and New York, Routledge.

JONES, Paul K. y PUSEY, Michael (2010): "Political communication and 'media system': the Australian canary", en Media, Culture \& Society, University of New South Wales, vol. 32, 3, pp. 451-471.

MÜLLER, Alberto (2006): "La Libertad de prensa en Estados Unidos", en Diario Las Américas, 18 de Abril: http://albertomuller.net/sociales/la-libertad-de-prensa-enestados-unidos/ [fecha de consulta: 12 de febrero 2011]

OSBORNE, Graeme y LEWIS, Glen (1995): Communication Traditions. Melbourne, Oxford University Press Australia.

SAHAGÚN, Felipe (2009): "El futuro del periodismo" en Cuadernos de Periodistas $\mathrm{n}^{\circ}$ 17, Madrid, Asociación de la Prensa de Madrid, pp. 9-24.

SALDAÑA DÍAZ, Nieves (2004): «A legacy of suppression» (II): Del control de la información y opinión en la América colonial y prerrevolucionaria. La emergencia de la libertad de prensa", en Derecho y Conocimiento $n^{0} 3$ : http://www.uhu.es/ derechoyconocimiento/DyC03/DYC003_B03.pdf. [fecha de consulta: 18 de febrero de 2011]

SALDAÑA DÍAZ, Nieves (2006): "La gestación de la primera enmienda: "Founding period" y "Original meaning" en Historia Constitucional $\mathrm{n}^{\mathrm{o}} 7$ : http://hc.rediris.es/ 07/articulos/html/Numero07.html. [fecha de consulta: 2 de febrero de 2011)

SANMARTÍ, José María; AGUADO, Guadalupe y MAGALLÓN, Raul (2010): “Análisis del modelo desregulador de prensa en España frente al modelo liberal británico y al intervencionista euromediterráneo". Textual and Visual Media, $\mathrm{n}^{\circ} 3$, pp. 239-252.

SARIKAKIS, Katharine (2004): British Media in a Global Era. London, Arnold.

TERROU, Ferdinand (1951): Le Droit de l'information. París, UNESCO.

WHEELWRIGHT, Ted y BUCKLEY, Ken (1987): Communications and the Media in Australia. Ed. Ted Wheelwright and Ken Buckley. 